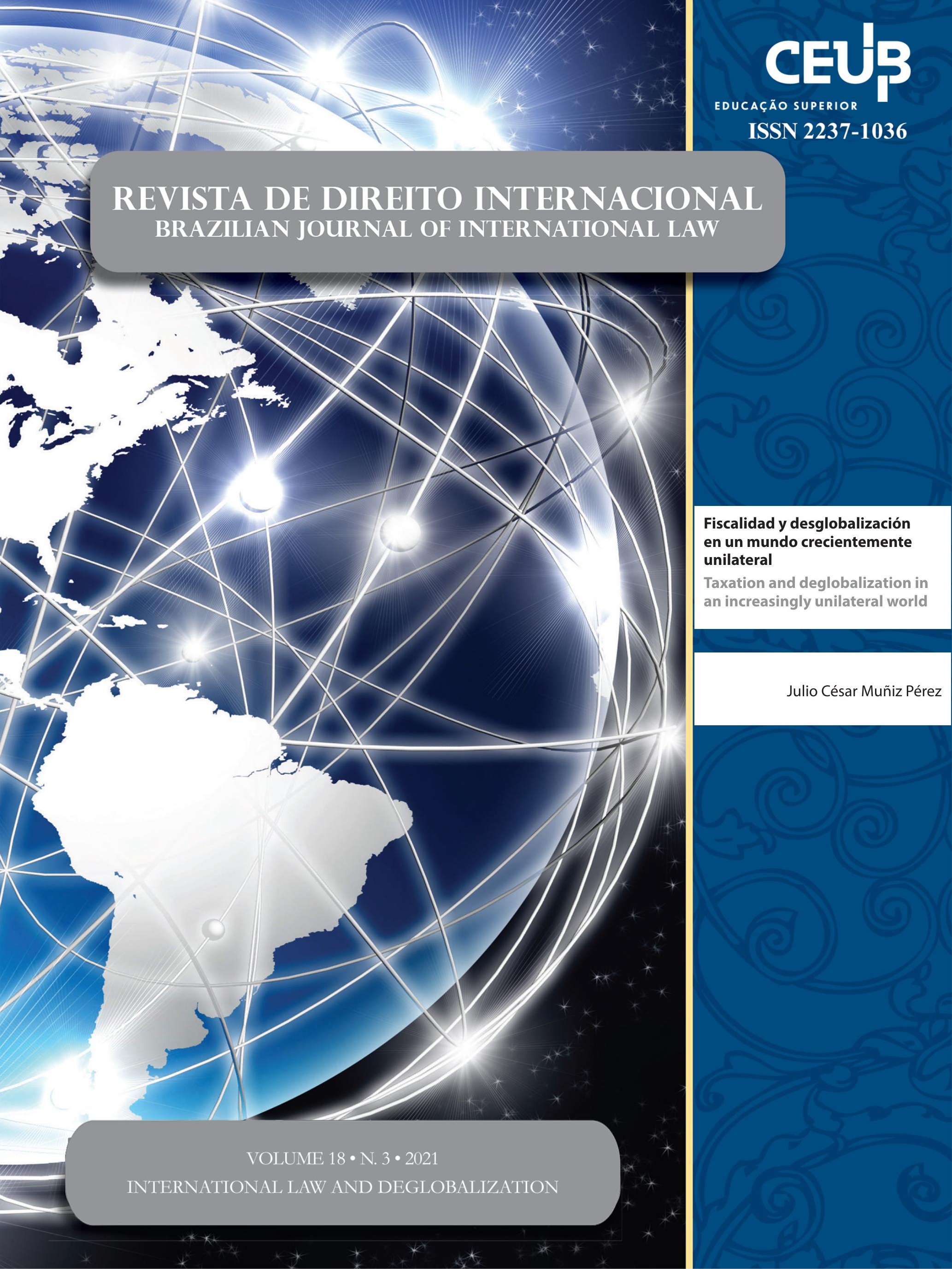




\section{Sumário}

Dossiê

EDITORIAL: INTERNATIONAL LAW AND DE-GLOBALIZATION 16 Ivette Esis, Jaime Tijmes e Juan Enrique Serrano

El régimen jurídico de la Inversión Extranjera Directa: ¿De la limitación a la desGLOBALIZACIÓN?

Ivette Esis Villarroel e Yoselyn Bermúdez Abreu

Desglobalização, Brexit e os novos acordos entre Reino Unido e União Europeia .34 Angela Limongi Alvarenga Alves e Daniel Freire e Almeida

FisCALIDAD Y DESGLOBALIZACIÓN EN UN MUNDO CRECIENTEMENTE UNILATERAL Julio César Muñiz Pérez

Covid, Covax e o Refluxo da Governança Global Salem Hikmat Nasser e Luiza Nogueira Papy

The International Monetary Fund and COVID-19: Old and New Challenges of a Post-World War II INTERNATIONAL INSTITUTION

Virdzhiniya Petrova Georgieva

Artigos Sobre outros temas

RULE OF LAW IN THE INTERNATIONAL ARENA: THE IMPORTANCE OF PRACTICES OF LEGALITY . 112 Angela Jank Calixto

THE WITHDRAWAL OF MEMBER-STATES FROM HUMAN RIGHTS COURTS: IS THE JUDICIALIZATION OF MEGA-POLITICS A NECESSARY CONDITION?. 132

Mikelli Marzzini Lucas Alves Ribeiro e Ernani Rodrigues de Carvalho Neto 
Princípio da precaução e mudança climática: uma análise do Acordo de Paris e das Conferências das Partes.

Jamille Bergamaschine Mata Diz e Carolina Mendonça de Siqueira

A INTERAÇÃo ENTRE OS ESPAÇOS CONSTITUCIONAIS NACIONAIS E INTERNACIONAIS E SEUS IMPACTOS NO SISTEMA DE FONTES DO DIREITO: AS LIÇÕES DA PROTEÇÃO COOPERATIVA DE DIREITOS HUMANOS E O CASO DA INTEGRAÇÃO EUROPEIA ...................................................... 173

Diego Fernandes Guimarães

WTO’s Engagement with National Law: Three Illustrations from India 193 Ravindra Pratap

GESTÃo MIGRATÓRIA E INTEGRAÇÃo REGIONAL: UMA ANÁLISE SOBRE A REGULAMENTAÇÃo NORmativa dos fluxos migratórios irregulares na União Europeia À luz do Novo Pacto Europeu sobre Migração e Asilo.................................................................. 212 João Mauricio Malta Cavalcante Filho e Eugênia Cristina Nilsen Ribeiro Barza

The African Regional Human and Peoples' Rights System: 40 years of progress and CHALLENGES. 232 Juan Bautista Cartes Rodríguez

The USMCA Sunset Clause 258 Jaime Tijmes-Ihl e Yvonne Georgina Tovar Silva

REFLEXÕES SOBRE A UNIVERSALIDADE DO DIREITO INTERNACIONAL DOS DIREITOS HUMANOS A RESPEITO DA PROTEÇÃO ÀS MULHERES 273 Érica Rios de Carvalho

A CRItical legal anAlysis OF GENDER EQUALITY IN INTERNATIONAL TRADE AgREEMENTS...287 Parul Shukla e Sheikh Sultan Aadil Huque

FEMinicídio, FEMicídio E Ódio NA AGENDA: o ASSASSinAto DAS MUlHERES NA AmÉriCA LATINA...... 309 Vinícius Ferreira Baptista

LEGAL IDEOLOGY IN THE CONTEXT OF DEVELOPMENT OF THE LEGAL STATE AND FORMATION OF THE CIVIL SOCIETY IN UKRAINE 
Direito INTERNACIONAL PÚBLICO NO ENTREgUERRAS (1919-39): A INSTITUCIONALIZAÇÃO DOS PROJETOS JURÍDICOS DE PAZ E MANEJO DOS POVOS NÃO SOBERANOS.

Hugo Luís Pena Ferreira

O Caso Gomes Lund (“Guerrilha Do Araguaia”) dez anos depois: Desafios para o cumPRIMENTO INTEGRAL PELO ESTADO BRASILEIRO

João Gabriel Archegas, Felipe Klein Gussoli e Vivian Cristina Lima López Valle

DiÁlogos museológicos: o Regime jurídico brasileiro e o Código de Ética do ConseLHo InTERnacional de Museus.

Paula Gonçalves do Carmo, Emerson Gabardo e Daniel Wunder Hachem 


\title{
Fiscalidad y desglobalización en un mundo crecientemente unilateral*
}

\author{
Taxation and deglobalization in an \\ increasingly unilateral world
}

Julio César Muñiz Pérez**

\section{Resumen}

En este trabajo partimos de la fundamentación de las dos afirmaciones implícitas en el título: la existencia de la desglobalización y el unilateralismo como elemento característico de ésta. A partir de este marco conceptual y desde la hipótesis de la desglobalización como fenómeno, pasamos a mostrar algunos ejemplos que demuestran cómo el ámbito de la fiscalidad internacional es particularmente permeable a este tipo de prácticas dada su estrecha vinculación con la soberanía. Con este objetivo se exponen tres manifestaciones de carácter unilateral en el ámbito de la fiscalidad: El debate sobre la coloquialmente conocida como "tasa Google", en el intento de construcción de un impuesto sobre servicios digitales hasta ahora infructuoso; el problema de la definición del concepto paraíso fiscal, en el que tampoco existe acuerdo; y un esbozo sobre la situación en la Unión Europea. De esta forma tratamos de demostrar el tradicional pero creciente unilateralismo en el ámbito de la fiscalidad internacional. Todo ello asumiendo como método la heurística textual y la hermenéutica jurídica. De este modo, acentuamos el papel de la fiscalidad como herramienta clave en el proceso de desglobalización, su función proteccionista y geoestratégica, las dificultades existentes para lograr acuerdos en un ámbito que debe ser tenido en cuenta tanto por inversores privados como por Estados y su relevancia para la economía mundial. Como resultado consideramos justificado y fundamentado el uso del término "desglobalización", así como su necesaria conexión con la fiscalidad internacional.

Palabras clave: fiscalidad; desglobalización; unilateralismo; globalización; impuestos.

\section{Abstract}

* Recebido em 30/05/2021

Aprovado em 27/09/2021

** Dr. en Derecho tributario europeo por la Universidad de Bolonia. Dr. en Historia antigua por la Universidad de Murcia. Profesor departamento Derecho de Empresa (UNED), y secretario de la comisión académica del programa de doctorado "Derecho y Ciencias Sociales de la UNED".

Email: juliocesarmunizperez01@gmail.com
In this paper we start from the basis of the two statements implicit in the title: The existence of de-globalization and unilateralism as a characteristic element of it. Based on this conceptual framework, we go on to show some examples that demonstrate how the field of international taxation is particularly permeable to this type of practice, given its close link with sovereignty. With this purpose, three unilateral manifestations in the field of taxation are presented: The debate on the colloquially known as the "Google Tax", in the attempt to construct a tax on digital services, so far unsuccessful; the 
problem of the definition of the concept of tax haven, on which there is no agreement either; and a sketch of the situation in the European Union. In this way we try to demonstrate the traditional but growing unilateralism in the field of international taxation. All this assuming textual heuristics and legal hermeneutics as a method. In this way, we emphasize the role of taxation as a key tool in the process of de-globalization, its protectionist and geostrategic function, the difficulties in reaching agreements in an area that must be taken into account by both private investors and States, and its relevance for the world economy.

Keywords: taxation; taxes; globalization; de-globalization; unilateralism.

\section{Introducción}

El ámbito de la fiscalidad constituye uno de los ámbitos más ligados a la soberanía y por ello más susceptibles a prácticas de carácter unilateral. De hecho, la fiscalidad no sólo es consecuencia de la soberanía, sino que constituye herramienta imprescindible para su conservación, puesto que aporta los recursos necesarios para el funcionamiento y la existencia misma del Estado. Debemos remarcar la vinculación del concepto soberanía con fiscalidad. La fiscalidad y la posibilidad de establecer tributos, la determinación de éstos, así como los caracteres y elementos que los configuran constituyen una competencia exclusiva de los órganos legislativos de los Estados.

Es por esta vinculación con la soberanía y la práctica estatal que es uno de los ámbitos más refractarios a la cooperación internacional, como pretendemos mostrar en este artículo, y cuyas variaciones permiten determinar cambios de ciclo de fases más aperturistas económicamente a otras más proteccionistas. Esta situación conlleva además a la difícil convivencia de esa capacidad para autorregularse soberanamente los Estados, vinculada a la soberanía y a la fiscalidad, frente a la realidad de un mercado global.

Como punto de partida resulta necesario precisar algunos términos como "desglobalización" o "unilateralismo". Desde esta clarificación conceptual, podemos afirmar que el unilateralismo, desde cierta conceptualización, es creciente. Sentado lo anterior, que opera como hipótesis de partida, pasamos a mostrar cómo la fiscalidad, es acaso el ámbito tradicionalmente más refractario a procesos de integración, dada su vinculación con la soberanía. En esta ejemplificación se ofrecen ejemplos de unilateralismo en las relaciones internacionales que pasan a ser estudiados de forma más detallada. Destacamos entre ellos tres de los grandes retos que a nivel internacional ocupan los esfuerzos de cooperación. El más destacable es la necesidad de adaptar los modelos tributarios a la economía digital, actualmente en plena efervescencia. Junto a éste se ejemplifica un caso tradicional, como es el problema de adoptar una definición específica de "paraíso fiscal" en la lucha contra la evasión y elusión fiscales. Finalmente hacemos una reflexión somera sobre el ámbito europeo que, aunque más amplio, ejemplifica los problemas de integración en el ámbito fiscal. Tres casos con los que se puede apreciar la dificultad para alcanzar acuerdos a nivel internacional en el ámbito fiscal, la incapacidad para adoptar medidas y el recomendable cambio de actitud de los Estados a la forma en que tratan la cuestión fiscal, todavía demasiado centrados en cuestiones internas poco o nada conscientes con la nueva situación de una economía digitalizada y con una amplísima movilidad de personas, bienes y capitales.

\section{Fundamentos conceptuales}

Desglobalización y unilateralismo pueden resultar a priori términos perfectamente compatibles, a la par que podemos considerar unilateralismo y globalización como antónimos. Sin embargo, esta relación no es tan pacífica y resulta necesario realizar unas consideraciones conceptuales previas, especialmente cuando algunos autores niegan la existencia de la desglobalización ${ }^{1}$.

\subsection{Desglobalización}

En primer lugar, en relación con el término globalización (implícito al hablar de desglobalización) debemos señalar la fuerte polisemia que podemos encontrar en su uso por parte de los autores.

\footnotetext{
1 Por ejemplo: MARTIN, Mervyn. Keeping it real: debunking the deglobalization Myth, Brexit and Trump: "Lessons" on integration. Journal of International Trade Law and Policy, v. 17, n. 1/2, p. 62-68, 2019. Disponible en: http://www.emeraldinsight.com/1477-0024. htm.
} 
Podemos repasar junto a Karamjeet $\mathrm{Kaur}^{2}$ algunas de las definiciones clásicas, como la de $\mathrm{Held}^{3}$, en el sentido de una simple ampliación, profundización y más veloz interconectividad, en la línea de Giddensin ${ }^{4}$, que la considera como la intensificación de las relaciones sociales a nivel mundial. También como el acortamiento de las distancias ${ }^{5}$.

Sin extendernos más en definiciones, que atienden a resaltar algunos elementos clave para cada autor en función de su disciplina de conocimiento, por nuestra parte lo entendemos en sentido netamente económico, como "una economía global cada vez más integrada, caracterizada por el libre comercio, el libre flujo de capitales y la posibilidad de aprovechar mercados laborales y regímenes fiscales extranjeros más baratos"

Dejamos pues conceptos demasiado vagos, en los que el término referencia simplemente un mundo cada vez más integrado e interdependiente ${ }^{7}$, o concepciones idealistas que aspiran a la desaparición de las fronteras o una especie de gobierno mundial. Concepciones en las que suele haber variaciones terminológicas, y que llegan a identificar globalización con un concepto distinto, como es el de integración, ciertamente vinculado a la globalización, pero diferente como fenómeno.

Este proceso de globalización, entendiéndolo por nuestra parte como globalización económica, aunque generalizable en términos de mayor conectividad internacional, se experimenta desde principios del siglo XX. En palabras de $\mathrm{Marichal}^{8}$, entendemos por globalización la intensificación de los intercambios de capital,

\footnotetext{
${ }^{2}$ KAUR, Karamjeet. Globalization \& deglobalization. Chandigarh: Sapatrishi Publications Chandigarh, 2020. p. 5 y ss.

3 HELD, David; MCGREW, Anthony G. (ed.). The global transformations reader: an introduction to the globalization debate. Blackwell Publishers, 2000.

${ }^{4}$ GIDDENS, Anthony. The consequences of modernity. Cambridge: Polity Press, 1991.

5 LECHNER, Frank J.; BOLI, John. The globalization reader. Hoboken: Wiley, 2012.

${ }^{6}$ Definición del diccionario merriam-webster, adaptada por el autor. Disponible en: https://www.merriam-webster.com/dictionary/ globalization, entrada "globalization".

7 Por ejemplo, hablando de forma general: HAASS, Richard N. Globalization's consequences and challeges for governance, en globalization, governance and civil society. Japan Center for International Exchange, 1998. Disponible en: https://www.jcie.org/analysis/books-reports/ globalization/.p. 101.

8 MARICHAL, Maria Eugenia. La OMC y el proceso de globalización de la regulación alimentaria. Revista de Direito Internacional, Brasilia, v. 12, n. 2, p. 306-321, 2014. Disponible en: https://www.publicacoesacademicas.uniceub.br/rdi/article/view/3146/pdf. p. 308.
}

información y personas a nivel planetario. Es decir, su origen se produce en un contexto en que también había espacio para prácticas de carácter unilateral, incluso con mayor intensidad que la actualidad. La Historia nos muestra que no podemos establecer una relación necesariamente antitética entre unilateralismo y globalización. De hecho, los inicios del siglo XX la práctica unilateral era la habitual, asociándose los Estados para cuestiones concretas, pero actuando mayoritariamente por sí solos.

No será hasta pasada la II Guerra Mundial, y culpando entre otras causas a las prácticas unilaterales de los Estados del estallido del conflicto, cuando se instrumentalicen foros multilaterales. Unos foros que, impulsados por un nuevo contexto internacional bipolar, proliferarán durante todo el siglo XX y que vienen a conformar la constelación de Organizaciones Internacionales actualmente existentes, así como foros internacionales bi o multilaterales. Unos foros en los que los Estados intentan unir esfuerzos frente a retos o amenazas que no pueden solventar individualmente.

Por ello se generaliza la multilateralidad, y la globalización desde la II Guerra Mundial fomenta de forma preferente la multilateralidad, así como los proyectos de integración económica como la Unión Europea. Una unión entre Estados que también es política o social, pero desde el primer momento se considera que el elemento esencial es el económico. De hecho, en el origen de la Unión Europea se manifiesta como primer objetivo la integración económica en el considerando de que una vez logrado éste, los restantes se lograrían por sí solo, como manifiesta la Declaración del 9 de mayo de 1950 pronunciada por Robert Schuman, en la que afirma que, desde la unificación económica "se llevará a cabo la fusión de intereses indispensables para la creación de una comunidad económica y se introducirá el fermento de una comunidad más profunda entre países que durante tanto tiempo se han enfrentado".

\footnotetext{
9 SCHUMAN, Robert. Declaración del 9 de mayo de 1950 pronunciada por Robert Schuman. Cuestiones sobre Europa, Fondation Robert Schuman n. 204, p. 1-3, 2011. Disponible en: https://www.robertschuman.eu/es/doc/questions-d-europe/qe-204-es.pdf.
} 
Es por ello que nos sumamos al conjunto de autores como Bello ${ }^{10}$, James ${ }^{11}$, Van Bergeijk ${ }^{12}$ que cuestionan el mantenimiento de la globalización y el inicio de una fase de desglobalización. Una fase que, del mismo modo que la globalización que hemos conocido post II Guerra Mundial se caracterizaba por el multilateralismo, vendría a caracterizarse por el unilateralismo.

La paternidad del término "desglobalización" se atribuye al economista Walden Bello ${ }^{13}$, aunque la forma en la que cada autor la entiende puede variar notablemente, desde concebirlo como un cambio de estructura de la realidad internacional a configurarlo como fases sucesivas, de globalización y desglobalización, que tienden a sucederse históricamente ${ }^{14} \mathrm{O}$ a describirlo como el deseo de diferentes Estados por dar marcha atrás en las políticas económicas dando importancia y preferencia a sus intereses internos. Una preferencia que siempre se acompaña del establecimiento de barreras cuantitativas que limitan el libre movimiento de personas, capitales, bienes y servicios.

Harold James ${ }^{15}$ detecta la existencia de evidencias de la existencia del fenómeno de la desglobalización a partir de la crisis financiera de 2008. Se fundamenta en datos económicos como la reducción en los flujos financieros transfronterizos, el menor crecimiento del comercio o el incremento de medidas proteccionistas, pero también lo que denomina "desglobalización política", con discursos contrarios a la migración y contra los métodos hasta ahora empleados para gestionar la globalización.

Frente a estas interpretaciones favorables a la existencia de una fase de desglobalización, encontramos

${ }_{10}$ BELLO, Walden. Deglobalization: ideas for new world economy (global issues). London: Zed Books, 2001.

11 JAMES, Harold. Deglobalization: the rise of disembedded unilateralism. Annual Review of Financial Economics, v. 10, p. 219-237, 2018. DOI: https://doi-org.ezproxy.uned.es/10.1146/annurevfinancial-110217-022625.

12 VAN BERGEIJK, Peter A. G. Deglobalization 2.0: trade and openness during the great depression and the global recession. Cheltenham: Edward Elgar Publishing, 2019.

13 BELLO, Walden. Deglobalization: ideas for new world economy (global issues). London: Zed Books, 2001.

14 WILLIAMSON, Jeffrey G. Globalization, labor markets and policy backlash in the past. Journal of economic perspectives, v. 12, n. 4, p. 51-72, 1998. Disponible en: https://www.aeaweb.org/ articles?id=10.1257/jep.12.4.51.

15 JAMES, Harold. Deglobalization: the rise of disembedded unilateralism. Annual Review of Financial Economics, v. 10, p. 219-237, 2018. DOI: https://doi-org.ezproxy.uned.es/10.1146/annurevfinancial-110217-022625. autores ${ }^{16}$ que prefieren hablar de un "repliegue" o "retroceso" de la globalización.

En este sentido, y como señala Appelbaum ${ }^{17}$, hay una contradicción entre globalización y el unilateralismo. De hecho, en el ámbito anglosajón, tanto en Reino Único como en los Estados Unidos oscilan entre el aislamiento y la participación internacional. Particularmente paradójico en el caso de los Estados Unidos, al que habitualmente se le considera el beneficiario de la globalización. De hecho, otra parte de la doctrina reduce el término a sinónimo de imperialismo, americanización, McDonaldización o expansión del neocapitalismo libera $1^{18}$.

Finalmente cabe señalar la posición que niega la existencia de "desglobalización" alguna. Así, lo que hace Mervyn Martin ${ }^{19}$, es distinguir globalización de algunas de las manifestaciones concretas.

Martin considera que ciertamente, la globalización fomenta la integración, pero interpreta los dos hitos más opuestos a los procesos de integración recientes, la dirección de la política de la Administración Trump y el Brexit, no como fenómenos de desglobalización, sino, simplemente, como procesos contrarios a la integración. Considera que el término desglobalización tiene connotaciones negativas por limitar la integración, pero supondría confundir el fenómeno (la globalización) con una de sus manifestaciones (la integración). Ciertamente, la integración adquiere su lógica en un contexto globalizado y es consecuencia de la globalización. Siendo esto cierto, pasa a plantear que la integración total y un mundo sin fronteras es imposible, señalando que la integración, como fenómeno causado por la globalización, pero no identificado con él, puede cambiar hacia otras fórmulas de globalización. De hecho, propone el término de

${ }_{16}$ VAN BERGEIJK, Peter A. G. Deglobalization 2.0: trade and openness during the great depression and the global recession. Cheltenham: Edward Elgar Publishing, 2019.

17 APPELBAUM, Richard P.; ROBINSON, William I. (ed.). Critical globalization studies. New York: Routledge, 2005. p. 26.

18 MORAWASKA, Eva. Transnationalism. In: WATERS, Mary C.; UEDA, Reed (ed.). The new americans: a guide to immigration since 1965. Cambridge: Harvard University Press, 2007. Similar en GILPIN, Robert. The challenge of global capitalism in the $21^{\text {st }}$ century. Princeton: Princeton University Press, 2002. una interpretación que acerca globalización como una nueva forma de imperialismo occidental.

19 MARTIN, Mervyn. Keeping it real: debunking the deglobalization Myth, Brexit and Trump: "Lessons" on integration. Journal of International Trade Law and Policy, v. 17, n. 1/2, p. 62-68, 2019. Disponible en: http://www.emeraldinsight.com/1477-0024.htm. 
"interconectividad selectiva" para hacer referencia precisamente a esta nueva realidad post-brexit. Este planteamiento es interesante ya que en la propia conformación de la Unión Europea existe una "interconectividad selectiva" manifestada en los Estados que ingresan en la Unión y la posibilidad de establecer vetos por todos los miembros a la incorporación de un nuevo Estado. Estaríamos pues ante una "desconexión selectiva" por parte de Reino Unido, fenómeno que, sin entrar en otros efectos en las relaciones internacionales apuntados en otro lugar ${ }^{20}$, vuelve a ser asimilable (siempre en nuestra opinión y ante la indeterminación del término) al concepto que pretende combatir de "desglobalización".

Resulta paradójico encontrar esta diversidad de posiciones en cuanto al término de "desglobalización", ya que nos recuerda el debate que se produjo en torno al concepto de "globalización" 21 en el que escépticos y globalistas discutían sobre su intensidad, o la existencia de diversas globalizaciones, de forma similar a como ahora discutimos el inicio de una fase desglobalizadora.

\subsection{Unilateralismo}

Finalmente, y continuando en el plano conceptual, debemos considerar el concepto de "unilateralismo". Encontramos también diversidad de definiciones, desde las más generales que lo consideran como el conjunto de medidas centradas en el sujeto que las adopta, y que lo hace habitualmente desde una perspectiva cortoplacista $^{22}$, hasta otras más específicas. Podemos entenderlo como una política o acción adoptada de forma unilateral sin apoyo del exterior o reciprocidad ${ }^{23}$. Quizá, entre otras definiciones, resulta interesante para este trabajo la aportada para el ámbito de las relaciones internacionales por Tago ${ }^{24}$ según el cual el término describe una

${ }^{20}$ MUÑIZ PÉREZ, Julio César. Brexit y la fractura del statu quo. Revista de Pensamiento Estratégico y Seguridad CISDE, v. 5, n. 2, p. 63-79, 2020. Disponible en: http://uajournals.com/ojs/index.php/cisdejournal/article/view/636.

${ }^{21}$ HELD, David; MCGREW, Anthony G. (ed.). The global transformations reader: an introduction to the globalization debate. Blackwell Publishers, 2000. p. 1-50

22 APPELBAUM, Richard P.; ROBINSON, William I. (ed.). Critical globalization studies. New York: Routledge, 2005. p. 26.

23 Definición del diccionario merriam-webster, traducida libremente por el autor. Disponible en: https://www.merriam-webster. com/dictionary/unilateralism.

${ }^{24}$ TAGO, Atsushi. Multilateralism, Bilateralism, and Unilateralism in Foreign Policy. Oxford Research Encyclopedias, 2017. Disponible en: https://doi.org/10.1093/acrefore/9780190228637.013.449. situación donde un Estado, normalmente una potencia, no respeta las normas adoptadas de forma multilateral y adopta una política exterior centrada en sí misma. En este punto debemos hacer una reflexión en cuanto a esa falta de respeto a las normas, ya que tiende a transmitir una visión antijurídica de la medida unilateral, cuando éstas suelen ser perfectamente jurídicas por dos circunstancias, la primera es que buena parte de las normas internacionales deben ser consideradas dentro de la categoría del soft law, precisamente por la habitual utilización de una expresión tan amplia como la de "norma". En estos casos, el carácter soft law implica la ausencia de obligatoriedad jurídica, de modo que se limitan a configurarse como simples recomendaciones o consejos sin valor vinculante. La segunda es referida a los acuerdos que sí son vinculantes, caso de los distintos tratados internacionales. Tratados que por otra parte no suelen incorporar sanciones en caso de incumplimiento para los Estados signatarios, pero cuyo cumplimiento sí es obligatorio. En este punto debemos considerar que existe la legítima opción de activar los mecanismos de denuncia de estos Tratados, cuya existencia y respeto al procedimiento y los plazos correspondientes garantiza la juridicidad de la medida, por muy unilateral que sea. Estas precisiones consideramos que son importantes ya que en nuestra opinión no es posible configurar las prácticas unilaterales de los Estados como necesariamente antijurídicas, como tampoco es posible considerarlas exclusivas de las potencias, especialmente desde la perspectiva tributaria que nos ocupa.

Adicionalmente cabe hacer la reflexión necesaria sobre la vinculación del unilateralismo con otros términos como bilateralismo y multilateralismo. Ya que éstos no son objeto prioritario de este trabajo nos limitamos a apuntar esta conexión.

Desde la realidad de que las prácticas unilaterales son en la mayoría de las ocasiones perfectamente legítimas, es natural que las encontremos en todo momento histórico. A pesar de ello la tendencia a desarrollar medidas unilaterales parece haber aumentado en los últimos años, encontrando varios fundamentos para considerar que actualmente nos encontramos en una fase de desglobalización. Los ejemplos que la mayor parte de autores consideran determinantes, como puntos de inflexión hacia una fase desglobalizadora, se caracterizan por la adopción de medidas unilaterales de particular relevancia. 
En este sentido podemos considerar que el unilateralismo es un fenómeno creciente desde el inicio del presente siglo. Así, en 2003 George W. Bush rechazó adherirse al protocolo de Kyoto y, en nuestra opinión más significativo, se retiró del Tratado antimisiles balísticos con Rusia. A nivel civil, encontramos vetos a acuerdos de la Organización Mundial del Comercio, medidas proteccionistas contra México, (y su competitivo modelo fiscal de empresas maquiladoras). Durante la era Obama tanto a nivel interno ${ }^{25}$ como internacional podemos encontrar ejemplos, como la realización de operaciones encubiertas.

Pero es la llegada de Trump a la Presidencia de los Estados Unidos y el Brexit los hitos reiterados por toda la doctrina como especialmente característicos. Bergei$\mathrm{jk}^{26}$, James ${ }^{27}$ o Kaur $^{28}$ viene a señalar el acceso a la presidencia de Donald Trump y el Brexit (acaso también el ascenso de Bolsonaro en Brasil) como ejemplos o síntomas del inicio de una ola de desglobalización. Una desglobalización marcada por el unilateralismo y particularmente por el unilateralismo fiscal, con incrementos arancelarios y medidas proteccionistas que encuentran en la fiscalidad uno de los principales instrumentos.

Kaur $^{29}$ señala que las tres principales fuerzas impulsoras de la globalización son las tecnologías de la información y la comunicación; la desmantelación de las barreras comerciales y la liberalización que ella implica facilitando la competencia y protegiéndola. En este sentido han actuado las "instituciones Bretton Woods", Banco Mundial, Fondo Monetario Internacional y Organización Mundial del Comercio con sus políticas.

Podemos considerar que la pandemia a supuesto incorporar limitaciones extraordinarias e inesperadas a la movilidad internacional. Una movilidad reducida que si

\footnotetext{
25 KELLEY, Christopher S. Rhetoric and Reality? Unilateralism and the Obama Administration. Social, Economic, and Political Transition in America: Retrospective on the "Era of Obama", v. 93, n. 5, special issue, p. 1146-1160, dec. 2012. Disponible en: https://www.jstor.org/ stable/42864120.

26 VAN BERGEIJK, Peter A. G. Deglobalization 2.0: trade and openness during the great depression and the global recession. Cheltenham: Edward Elgar Publishing, 2019. p. 11.

${ }^{27}$ JAMES, Harold. Deglobalization: the rise of disembedded unilateralism. Annual Review of Financial Economics, v. 10, p. 219-237, 2018. DOI: https://doi-org.ezproxy.uned.es/10.1146/annurevfinancial-110217-022625.

${ }^{28}$ KAUR, Karamjeet. Globalization \& deglobalization. Chandigarh: Sapatrishi Publications Chandigarh, 2020.

${ }^{29}$ KAUR, Karamjeet. Globalization \& deglobalization. Chandigarh: Sapatrishi Publications Chandigarh, 2020. p. 7.
}

se confirman las expectativas de incremento de costes en los combustibles fósiles llevará a una menor movilidad para la mayor parte de la población, incrementada por las previsibles subidas de impuestos ambientales.

En definitiva, un conjunto de medidas respecto a las cuales cabe dudar de si implican un cambio de ciclo, pero que en todo caso pueden ser calificadas como unilaterales.

\section{La fiscalidad en el proceso}

El concepto de soberanía es tan amplio que un análisis completo del mismo es inviable en esta sede. Asumamos una concepción de soberanía entendida como el conjunto de potestades soberanas, frente a la concepción tradicional de soberanía como elemento indivisible, casi místico, vinculado a la existencia misma del Estado. Separar estas facultades permite diferenciar las propiamente soberanas de aquellas otras no vinculadas necesariamente con la soberanía, la existencia del Estado y los atributos que le son propios, como el control efectivo del territorio, población o su independencia.

Como señala López Espadafor ${ }^{30}$, el derecho internacional tributario suele vincularse dogmáticamente con el concepto de soberanía, especialmente con la "soberanía fiscal". Una soberanía que podemos simplificar como la potestad de un Estado para imponer actos (en nuestro caso de carácter fiscal) dentro de su ámbito territorial de poder. Cada Estado goza de un ilimitado poder impositivo ${ }^{31}$ a nivel interno, pero en el plano internacional es una potestad compartida entre las distintas soberanías y mutuamente limitada. Por ello, la soberanía es el fundamento (fundamento histórico, y a pesar de que a nivel jurídico ese fundamento lo encontramos en las Constituciones nacionales, habitualmente es previo a ellas) sobre el que el Estado impone los tributos a nivel interno, y sobre el que el Estado procede a desarrollar relaciones fiscales con otros Estados, a la par que excluye su acción. De hecho, es precisamente en

\footnotetext{
30 LÓPEZ ESPADAFOR, Carlos María. Recorrido transnacional de la soberanía tributaria. Cuadernos de Derecho Transnacional, p. 306330, mar. 2018. DOI: https://doi.org/10.20318/cdt.2018.4124. p. 314.

31 GARBARINO, C. La tassazione del reddito transnazionale. Padova: CEDAM, 1990. p. 96 y ss. Citado por LÓPEZ ESPADAFOR, op cit., p. 314.
} 
el nivel externo donde mejor se aprecia esta conexión soberanía-fiscalidad.

De este modo nos encontramos con dos perspectivas. La interna, que podemos entender como el poder ilimitado de un Estado, para realizar actos legislativos, ejecutivos y judiciales dentro de su ámbito de poder territorial $^{32}$. Este plano interno implica la supremacía del Estado sobre los sujetos pasivos y la relación de imperium. Y la perspectiva internacional o externa, en las que distintas soberanías, y sus respectivos poderes tributarios, conviven en el contexto de la igualdad soberana formal ${ }^{33}$ predicable de todos los Estados, característico del ordenamiento internacional. Una convivencia excluyente del resto de Estados sobre sus respectivos ámbitos territoriales. Soberanía e independencia son elementos clásicos del concepto de Estado y su inclusión en la sociedad internacional. En este sentido la soberanía puede entenderse como poder impositivo preeminente sobre cualquier otro y podemos vincularla con la independencia del Estado y el ius excludendi alios, es decir, la exclusión de otros.

Por esta razón la fiscalidad se ve en la práctica vinculada estrechamente con la soberanía, sin existir un poder impositivo que se despliegue sobre los Estados o sus ciudadanos del mismo modo que no existe un poder soberano sobre los propios Estados.

Una vinculación tan estrecha, entre soberanía y fiscalidad, que la podemos entender desde la perspectiva de la importancia absoluta de la fiscalidad para la subsistencia del Estado, tanto en lo político, lo económico o lo militar, ya que sin capacidad para financiarse se anula

\footnotetext{
32 BÜHLER, Ottmar. La doble imposición: problemas jurídico-internacionales. Barcelona: Universidad de Barcelona, 1971. p. 3.

33 La igualdad formal, aunque caracterizada como una característica del imperialismo capitalista, como hace DAVID, Thomaz Delgado; SILVA, Maria Beatriz Oliveira da; BARCELLOS, Rosane Beatris da Rocha. A dimensâo jurídica do imperalismo na (des)orden global capitalista: uma análise com base na crítica marxista ao direito internacional e ás relaçôes político-económicas de dominaçâo e dependência. Revista de Direito Internacional, Brasilia, v. 15, n. 3, p. 379-440, 2018. Disponible en: https://www.publicacoesacademicas.uniceub. br/rdi/article/view/5882/pdf. p. 384, constituye el fundamento del unilateralismo y garantiza la soberanía estatal, frente a lo que señala SOUZA, Lucas Silva de; SALDANHA, Jânia Maria Lopes. O direito internacional do desenvolvimento e suas raíces imperialistas no contexto do pluralismo normativo: por un paradigma libertario e nâo (neo)liberal. Revista de Direito Internacional, Brasilia, v. 16, n. 1, p. 200222. Disponible en: https://www.publicacoesacademicas.uniceub. br/rdi/article/view/5928/pdf. p. 207, que avisa de los riesgos de la suplantación de la soberanía por una estructura globalizada que sirva a intereses particulares de grupos y conglomerados económicos.
}

de facto la independencia del Estado ${ }^{34}$. El sometimiento económico eliminaría por completo la libertad estatal. Este elemento fiscal opera en dos vertientes, tanto desde la necesidad de obtener recursos para realizar políticas como la utilización de la fiscalidad como herramienta política en sí misma (por ejemplo, respecto a finalidades más allá de la recaudación, es decir, como en la parafiscalidad, como desincentivación de ciertas actividades o el incentivo de otras).

Prueba de la estrecha relación entre fiscalidad y soberanía es la resolución 2625 (XXV) de la Asamblea General de la ONU, de 24 de octubre de 1970, en la que junto al establecimiento de los principios que deben regir las relaciones internacionales como el Principio de igualdad soberana de los Estados, de igualdad de derechos y libre determinación de los pueblos, debemos descartar la obligación "de no intervenir en los asuntos que son de la jurisdicción interna de los Estados". Dentro de este último principio, entre otras referencias podemos destacar la afirmación de que "Todo Estado tiene el derecho inalienable a elegir su sistema político, económico, social y cultural, sin injerencia en ninguna forma por parte de ningún otro Estado". Dentro del sistema económico el aspecto fiscal es el que queremos realzar, y que constituye uno de los fundamentos principales por la que se hace necesaria la cooperación entre Estados y su libre adhesión, siempre desde el principio de igualdad soberana. Lo que conlleva a su vez a las dificultades que implica tal aceptación de las reglas internacionales.

De todo lo anterior encontramos la explicación del porqué el ámbito de la fiscalidad ha resultado particularmente prolífico en supuestos refractarios a la globalización y en procesos de integración, en primer término y cómo en la actual fase de desglobalización aparecen ejemplos de "unilateralismo fiscal" con mayor facilidad que en otros ámbitos. Los ejemplos de los que nos ocupamos a continuación se refieren a fenómenos globales de unilateralismo, generales a toda la comunidad internacional o a la Unión Europea, dejando los numerosísimos casos de unilateralismo con medidas fiscales de carácter proteccionista.

\footnotetext{
34 Este es precisamente el problema que surge cuando un Estado cae en una situación de dependencia de la deuda externa o de organismos que lo financien, que desde un plano teórico nos conduciría a encontrarnos ante una soberanía de carácter meramente semántico.
} 


\section{Economía digital}

Resulta innecesario señalar la importancia que la revolución digital ha tenido en todos los niveles sociales y, entre ellos el económico. Las actividades económicas digitales, además de crecientes cuantitativamente y también en cuanto la cantidad de servicios que pueden ofrecerse virtualmente, son altamente volátiles y geográficamente móviles. De aquí el nacimiento de proyectos relativos a la fiscalidad de la economía digital, ante la necesidad de adaptar los sistemas impositivos a esta nueva realidad.

La fiscalidad de la economía digital debemos vincularla con la conocida periodísticamente como "Tasa Google". Un impuesto (no una tasa en sentido estricto) que vendría a gravar las rentas obtenidos por colosos informáticos en base al beneficio efectivo obtenido en cada territorio.

Estos intentos de adaptación se producen desde el último decenio del siglo XX. Históricamente se han planteado teorías para desarrollar una fiscalidad sobre el comercio electrónico con propuestas ya desfasadas hoy en día, como el Bit $\mathrm{Tax}^{35}$, que se fundamentaba en el número de bits intercambiados en cada transacción con independencia del valor real de la transacción. Otra propuesta histórica es la "tarjeta electrónica" de la administración Clinton, para intercambiar dinero electrónico a cada moneda nacional, o la "software proposal", que integra algunos programas en las páginas de los vendedores, o la creación de una Agencia Fiscal internacional sobre el comercio electrónico ${ }^{36}$ entre otras ${ }^{37}$.

Hemos señalado anteriormente cómo en el plano internacional las distintas soberanías fiscales conviven y se limitan, excluyéndose mutuamente unos a otras de sus respectivos ámbitos de soberanía (territorio, zona económica exclusiva, mar territorial,...). Sin embargo, desde los años noventa del siglo XX la digitalización

\footnotetext{
35 SOETE, Luc; KAMP, Karin. The bit tax. The case for further research. Science and Public Policy, v. 23, issue 6, p. 353-360. Disponible en: https://doi.org/10.1093/spp/23.6.353.

${ }^{36}$ CHAN, Clayton W. Taxation of global e-commerce on the internet: the underlying issues and proposed plans. Minnesota Journal of Global Trade, v. 9, n. 1, p. 233-268, 2000. Disponible en: https:// core. ac.uk/download/pdf/217210515.pdf.

37 JÜRGEN, Stehn. Leviathan in cyberspace: hot to tax e-commerce. Kieler Diskussionsbeiträge, n. 384, The Open Access Publication Server of the ZBW, Leibniz Information Centre for Economics, 2002. Disponible en: https://www.researchgate.net/publication/45122976_ Leviathan_in_cyberspace_how_to_tax_e-commerce.
}

de la economía ha producido una revolución, haciendo mucho más volátiles tanto los capitales como los sujetos (empresas y sujetos particulares) o incluso las actividades que éstos realizan.

El cada vez mayor peso de la economía digital conduce a la necesidad de adaptar los modelos tributarios que continúan centrados en categorías clásicas de la soberanía estatal, como es la presencia efectiva en el territorio. Sigue siendo necesario adaptar los sistemas fiscales de los Estados a la realidad digital. Para ello podemos reducir las propuestas existentes a dos opciones básicas, bien la menos recomendable creación de nuevas figuras impositivas, nuevos impuestos, que regulen esta nueva esfera de manifestación de riqueza, o la adaptación de categorías tradicionales del Derecho Tributario a la nueva realidad. En éste último caso, una de las opciones más plausibles en la actualidad es el denominado "Establecimiento Permanente Digital", que supone adaptar la categoría del Establecimiento permanente al entorno virtual.

El centro del debate está en lograr encajar esta moderna economía global con las exigencias tradicionales de presencia física en el territorio, exigencias vinculadas con las categorías soberanas, pero incapaces hasta el momento de responder a las nuevas realidades virtuales. Un entorno que crean una fractura entre el lugar en el que el valor se crea y donde los beneficios son sometidos a tributación.

Debemos subrayar la importancia de esta construcción, ya que podrá determinar el desarrollo futuro del comercio electrónico. Dada la situación de interconexión económica existente, es necesaria la existencia de un consenso internacional relativo a la forma y medida en la que gravar, por ejemplo, servicios digitales. Pero, frente a esta necesidad, se está manifestando reiteradamente la incapacidad para lograr un acuerdo en este sentido, incluso dentro del ámbito de la Unión europea. Un nuevo y trascendental ejemplo de unilateralismo que contrasta con los avances logrados en otros ámbitos.

Por ello no es de extrañar que uno de los principales objetivos de la Organización para la Cooperación y el Desarrollo Económico (OCDE) sea éste y venga realizando esfuerzos en este sentido. Constituye de facto el principal foro multilateral sobre estas cuestiones y es identificada como una de las áreas de actuación preferente en el marco del plan de acción contra la erosión de bases imponibles, conocido como Plan BEPS. Esta 
conexión de la economía digital y el combate a la erosión de bases imponibles no es accidental, ya que la volatilidad de las actividades digitales facilita la ubicación en jurisdicciones fiscalmente favorables. Es decir, el objetivo es responder a la erosión de bases que estas ubicaciones suponen y frenar la transferencia de activos a otras jurisdicciones, lo que en ocasiones encubre maniobras de carácter proteccionista, incrementa la presión sobre compañías y sobre Estados de baja tributación, así como supone adoptar criterios discriminatorios que distorsionan la libre competencia.

La OCDE propone dos opciones básicas para gravar la economía digital. Bien la reconfiguración del concepto Establecimiento Permanente, bien la creación de nuevos tributos a los que deben incorporarse acuerdos específicos (o adaptar los Convenios para evitar la doble imposición ya existentes), para evitar los efectos perniciosos y la desincentivación económica que supone la doble imposición.

La solución principal se orienta hacia tributos de carácter directo, si bien la propia OCDE ha admitido, ante las dificultades para llegar a un acuerdo y las urgencias de algunos Estados por adoptar medidas, la posibilidad de que los Estados, unilateralmente, puedan establecer impuestos de carácter indirecto sobre estas manifestaciones económicas.

La regulación del Establecimiento Permanente digital se centra en determinar la competencia fiscal y los puntos de conexión con el Estado. El primero, supone determinar en qué casos un Estado va a tener competencia fiscal para gravar una manifestación, con preferencia respecto a otro que deberá inhibirse o admitir la deducción del impuesto. El segundo implica establecer qué elementos objetivos van a originar una conexión suficiente con ese Estado, hasta el punto de hacer nacer una obligación fiscal en el mismo.

Los puntos de conexión son en nuestra opinión la cuestión más importante, base del nacimiento de la relación tributaria. En este punto se propuso la "presencia económica significativa" o "presencia digital significativa", aspecto que generaba problemas a la hora de lograr una estructura global útil para todas las jurisdicciones, tanto para países en desarrollo como desarrollados o con independencia de su tamaño. La búsqueda entre la precisión de los datos objeto de la manifestación económica deben ponderarse con la simplicidad necesaria para hacer viable al sistema. Para ello se ha realizado igualmente múltiples propuestas desde la OECD, que por otra parte, y como ya indicamos, tienen carácter de soft law, no son vinculantes y la carencia de acuerdo las sitúa en una posición muy difícil.

Esta cuestión también ha sido tratada por la Unión Europea, dando comienzo los trabajos en coordinación con las propuestas de la OCDE a partir de la Comunicación de la Comisión sobre "A Fair and Efficient Tax System in the European Union for the Digital Single Market", de 21 de septiembre de 2017. En 2018 se planteó la propuesta de una directiva para la tributación de las compañías con una presencia digital significativa ${ }^{38}$. Una directiva con la que se pretendía proteger el mercado interior y, especialmente, el mercado digital europeo, y evitar medidas unilaterales y descoordinadas por parte de los Estados miembros que dañasen el mercado único.

En el ámbito europeo debemos resaltar la importancia del concepto de "presencia digital significativa" ya que su origen es europeo y ha sido incorporado desde Europa a la OCDE. Un concepto que podemos entender como un "Establecimiento Permanente Digital" en sentido amplio. De hecho, las propuestas persiguen extender el concepto de Establecimiento permanente a nivel europeo y confiere alguno de los elementos típicos del tradicional "establecimiento permanente"; por ejemplo, el artículo 5 de ese proyecto de directiva hacía a los beneficios tributaria sólo en el marco de los beneficios empresariales de cada Estado miembro.

Este concepto de Establecimiento permanente digital en la propuesta europea tiene su fundamento en el número de usuarios de servicios digitales o demandantes de servicios digitales, lo que se identifica como la "huella digital" de una compañía en una jurisdicción. El siguiente paso era determinar los criterios para tener una "presencia digital significativa", en concreto, fundamentado en el criterio de los usuarios, admitiendo el uso de varios criterios que se enumeraban (Volumen de beneficios, número de usuarios o el número de contratos por servicios digitales).

Sin embargo, y prueba una vez más de los intereses estatales en juego, la vinculación con la soberanía y el recelo de los Estados, la propuesta de Directiva fracasó, al no poder alcanzar la regla de aceptación por unanimi-

\footnotetext{
38 "Proposal for a Council Directive laying down rules relating to the corporate taxation of a significant digital presence" COM/2018/0147 2018/0072 CNS).
} 
dad exigible. Con su fracaso se abre la puerta a la imposición unilateral por cada Estado miembro, situación en la que nos encontramos.

La realidad es que la Unión Europea y la protección del mercado único exigen un marco europeo regulatorio que permita gestionar y fomentar la economía digital. Desde esta perspectiva se está trabajando en una nueva propuesta de directiva por la Comisión, lo que implica una nueva iniciativa para alcanzar un acuerdo europeo en esta materia y la aceptación del Digital Levy. Trabajos que son paralelos a los realizados por la OCDE o el G20, todos ellos aspirando a lograr una tributación digital eficiente.

Mientras nos encontramos en esta situación los Estados han comenzado a regular unilateralmente estos tributos "sobre determinados servicios digitales", como en el caso español la Ley 4/2020. Cada normativa nacional tiene particularidades y variaciones notables, mostrándose una vez más la tendencia a adoptar soluciones unilaterales, unas soluciones que encubren tanto medidas proteccionistas como medidas de presión económica internacional en el ámbito de las relaciones internacionales frente a compañías y Estados.

Esta multiplicación de medidas unilaterales ha conducido a una nueva y muy reciente propuesta aparentemente favorable al establecimiento de un tipo mínimo global para empresas. Aprobado por el G7 las noticias periodísticas abundan ante la inaudita propuesta de adoptar un tipo mínimo sobre impuesto de sociedades del 15\%. La causa de esta propuesta está en la constate reducción que las rentas empresariales están sufriendo a nivel comparado en todos los Estados derivado de la internacionalización de la economía. La fácil deslocalización de las empresas hacia territorios de menor presión fiscal llevó a la limitación práctica del incremento de tipos impositivos societarios a nivel global.

Esta medida no constituye un acto unilateral, a pesar de ciertos elementos de unilateralidad, sino que aparece como fruto de la multilateralidad. Es en la respuesta que con certeza veremos en otros Estados, que se negarán a adoptar estas recomendaciones (por otra parte, una negativa totalmente legítima), ya que resultan evidentemente contrarias a sus intereses.

Consideremos en primer lugar que esta propuesta de Estados Unidos persigue eliminar el intento de llegar a un acuerdo sobre la fiscalidad de la economía digital, especialmente cuando se ha materializado en impuestos nacionales con ánimo manifiestamente discriminatorio y con el que se persigue gravar exclusivamente las rentas de grandes corporaciones digitales, norteamericanas. Impuesto al que acabamos de hacer referencia.

En segundo lugar, cabe destacar la reacción de China que, si bien respecto a otras cuestiones, acusa al G7 de manipulación y recuerda que los tiempos coloniales pasaron y "un pequeño grupo de países no puede decidir las políticas globales" ${ }^{\prime 39}$.

En tercer lugar, y de forma paralela, la Organización para la Cooperación y el Desarrollo Económico (OCDE) ha aprobado un acuerdo basado en dos pilares para poner fin a los problemas y retos que la digitalización de la economía conlleva ${ }^{40}$. Sin embargo, este documento, que recoge ese compromiso de establecer como tipo societario mínimo el del 15\% y eliminar todos los impuestos sobre servicios digitales o medidas similares a las compañías, plantea serias dudas de ser especialmente beneficioso para los Estados desarrollados. En esta línea, el propio documento aspira a eliminar la posible doble imposición con la recomendación de utilizar los sistemas de exención o crédito, y si bien faltan los detalles del reparto de competencia fiscal, el nexo en función de la cifra de negocio perjudica excesivamente a los Estados más pequeños (como por otra parte ya resulta de otros trabajos de la OCDE, como del sistema de reparto fiscal establecido en el modelo OCDE de convenio para eliminar la doble imposición y que motivó el modelo de convenio alterativo y de uso minoritario, de Naciones Unidas).

En cuarto lugar, no podemos olvidar que la fiscalidad cumple junto a otros elementos de la normativa de un Estado, una función muy relevante en la política de atracción de inversión extranjera. Esta quizá sea la principal razón por la que se plantea el carácter favorable para los Estados ya desarrollados, ya que asumir este impuesto mínimo global limita las actuaciones soberanas que los Estados en vías de desarrollo podrán adoptar en el futuro con el ánimo de atraer inversión extranjera.

\footnotetext{
39 Noticia del 14 jun. 2021. Disponible en: https://www.elmundo. es/internacional/2021/06/14/60c72d2e21efa09f4b8b4669.html.

40 OECD. Statement on a two-Pillar solution to address the tax challenges arising from the digitalization of the economy. OECD/G20 Base Erosion and Profit Shifting Project. 2021. Disponible en: https://www. oecd.org/tax/beps/statement-on-a-two-pillar-solution-to-addressthe-tax-challenges-arising-from-the-digitalisation-of-the-economyjuly-2021.pdf.
} 
Finalmente, en quinto lugar y desde una perspectiva más política, debemos considerar que la propuesta procede de Estados Unidos, que sufre una acusada polarización política. Este tipo de propuestas que chocan abiertamente con el ideario republicano, pueden verse abandonadas por un cambio en la Casa Blanca, así como la imposibilidad de adoptar una medida de este tipo sin el apoyo de China, quien por otra parte no es miembro de la OCDE, aunque participa en ella como país clave.

Por todas estas razones, y a pesar de que tendrá una evolución interesante, el establecimiento de este impuesto mínimo global a las sociedades lo consideramos inviable, y más bien lo entendemos como una huida hacia adelante, intentando neutralizar los impuestos sobre actividades digitales más que un verdadero intento por lograr un impuesto global.

Además, se manifiesta la actitud de los Estados de alta presión fiscal a la hora de tratar los problemas de la economía digital. Adoptan una posición hostil, basada en la concepción de que deben combatir las prácticas de elusión fiscal que reducen su recaudo fiscal Sin embargo, creemos que sería necesario reflexionar sobre esta concepción que habitualmente subyace en las negociaciones y la dificultad de distinguir argumentos de justicia social con el mero afán recaudatorio o celo intervencionista. De hecho, la movilidad de los factores productivos, que se extienden a nivel de personas físicas, difícilmente podrá mitigarse. Una movilidad que es vista desde algunos países como un riesgo que combatir y neutralizar en lugar de como una oportunidad para atraer talento e inversión extranjera. Ciertamente constituye ambas cosas. Por ello, sólo los Estados que sean capaces de crear un entorno favorable para el desarrollo de la economía digital y el comercio resultarán exitosos en digitalizar sus economías.

\section{La definición de "paraíso fiscal"}

El concepto de "paraíso fiscal" o "refugio fiscal" (a pesar de que no son estrictamente lo mismo ${ }^{41}$ ), son frecuentemente utilizados desde muy diversos ámbitos para hacer referencia a Estados o jurisdicciones de baja o nula tributación. La importancia económica de estos

${ }^{41}$ WARD, Don. How to protect your assets legally with an offshore Trust or International Business Corporation. London: Financial Bureau, 2013. p. 47. centros, habitualmente grandes centros financieros, es esencial, siendo vistos por los Estados de alta presión fiscal como herramientas útiles para evasores y elusores fiscales. Por esta razón, bastantes Estados han adoptado medidas para intentar neutralizar los beneficios del uso de estos grandes centros, pero, una vez más en una economía globalizada, las actuaciones unilaterales resultan insuficientes y en la práctica infructuosas.

Por esta razón la OCDE se ha ocupado del tema de los paraísos fiscales (así como otras Organizaciones Internacionales como la ONU) desde la década de los noventa del siglo XX. Para ello, la OCDE ha realizado informes ${ }^{42}$ señalando los elementos especialmente nocivos de estos regímenes, que les dota de un carácter pernicioso o nocivo al convertirse en herramientas esenciales de los evasores y elusores fiscales. Esta determinación de elementos llevó a que la OCDE abandonase el término de paraíso fiscal y hablase de jurisdicciones no cooperadoras y, en los casos más graves, el régimen fiscal pernicioso.

De hecho, se hace una enumeración de los elementos que se deben/pueden tener en cuenta para la determinación como tal de un territorio, recomendando la concurrencia de más de uno. Por ejemplo, para el caso de las jurisdicciones no cooperadoras la OCDE plantea cuatro posibles elementos que, de concurrir al menos dos, permitirían su calificación unilateral como tal: nivel bajo o nulo de tributación, inexistencia de intercambio de información, falta de transparencia en la aplicación del sistema fiscal o inexistencia de actividad económica sustancial. A estos elementos se suma, en el Régimen fiscal pernicioso el criterio de la estanqueidad o ring fencing.

Frente a esta determinación de los elementos (que ciertamente solo enumera algunos de los elementos clave), no se logra un acuerdo para determinar qué elementos o cuántos de ellos deben concurrir para poder considerarlo en la legislación interna como paraíso; como tampoco se logra la obligada remisión a la lista de paraísos de la OCDE.

Como se indica por Muñiz ${ }^{43}$, frente a la propuesta de la OCDE en el panorama comparado podemos encontrar tres tipos distintos de soluciones, el criterio

\footnotetext{
${ }^{42}$ El primer gran informe relativo a los paraísos fiscales es el trabajo de la OCDE. Harmful tax competition, an Emerging Global Issue, de 1998. ${ }^{43}$ MUÑIZ PÉREZ, Julio César. En busca del paraíso perdido: los paraísos fiscales hoy. Cizur Menor: Aranzadi, 2021.
} 
porcentual ${ }^{44}$, el criterio de los elementos (a determinar jurisprudencialmente caso por caso) y el criterio de lista. Éste último es el habitualmente seguido en los Estados europeos y latinoamericanos. Además, y esto nos resulta paradójico, esta elaboración de las listas, a pesar de que su inclusión representa para sus residentes un tratamiento fiscal agravado, más oneroso, su elaboración se deja en manos de los poderes ejecutivos sin intervención en ocasiones del órgano legislador.

Ante esta falta de homogeneidad nace lo que podemos denominar como el "principio de subjetividad" 45 del concepto de paraíso. Una subjetividad que lleva a la variación en la composición de las distintas listas y que reduce notablemente en la práctica la utilidad de las medidas antiparaíso. La diferente calificación por distintos Estados, al no asumir todos ellos la lista de la OCDE como única lista común, facilita la utilización de unos paraísos según qué Estados.

Adicionalmente, no podemos olvidar que algunos de los territorios habitualmente considerados como paraísos fiscales están bajo soberanía de Estados miembros de la OCDE. De este modo, sus decisiones implican alcanzar un equilibrio entre los intereses de los Estados de mayor tributación ansiosos de combatir los paraísos, y que han renunciado a competir fiscalmente con ellos, con los intereses de los propios Estados con intereses en estos centros ${ }^{46}$. La consecuencia lógica es una notable falta de acuerdo y el recurso sistemático a la unilateralidad, la existencia de distintas listas, incluso entre los Estados miembros de la Unión Europea y la propia Unión.

\section{Unión Europea}

La Unión Europea se configura como una Organización Internacional de integración en la que sus Esta-

\footnotetext{
44 La norma se limita en este caso a señalar el porcentaje de diferencia entre el tributo propio y el extranjero, a la hora de determinar si hay tal competencia fiscal y se activan los mecanismos "penalizadores" de las cláusulas antiparaíso. Tiene el aspecto positivo que no necesita actualización.

45 MUÑIZ PÉREZ, Julio César. En busca del paraíso perdido: los paraísos fiscales hoy. Cizur Menor: Aranzadi, 2021. p. 77.

${ }^{46}$ De hecho, uno de los elementos que pueden considerarse como coadyuvante del Brexit es la constante presión europea contra los paraísos. MUÑIZ PÉREZ, Julio César. Brexit y la fractura del statu quo. Revista de Pensamiento Estratégico y Seguridad CISDE, v. 5, n. 2, p. 63-79, 2020. Disponible en: http://uajournals.com/ojs/index.php/ cisdejournal/article/view/636.
}

dos miembros ceden parte de su soberanía. Ya hemos hablado del concepto de integración en general, que encuentra su lógica en las dinámicas globalizadoras. Encuentra su origen en la exigencia de coordinación por parte de Estados Unidos entre los Estados beneficiarios del Plan Marshall. Como ya indicamos sus objetivos iniciales son netamente económicos, la construcción del mercado interior, pero estando siempre presente un afán. No obstante, en la Unión europea no podemos olvidar (aunque en la actualidad parece olvidarse con mayor facilidad) la aspiración de integración política que representa la Unión. También hemos señalado cómo la salida de Reino Unido de la Unión es uno de los síntomas que con mayor fundamento nos permite afirmar esa "desglobalización".

Sin embargo, la Unión Europea representa una limitación (a la soberanía) para los Estados en múltiples sectores, o mejor una autolimitación ${ }^{47}$, legítima constitucionalmente y querida por los Estados. De hecho, nos limitaremos a esta cuestión ya que realizar un examen completo resulta inabordable. Una limitación que es trasladable al ámbito del Derecho internacional general y que ocurre también en el ámbito de la fiscalidad, en el que los intentos de armonización conllevan, como ya señalara Constantinesco ${ }^{48}$, la limitación de la soberanía fiscal de los Estados miembros, interviniéndose (y limitando) la libertad política de éstos.

El marco general lo establecen los Tratados constitutivos de la Unión, en los que queda claro (art. 3.3 del Tratado de la Unión) que el objetivo fundamental es el establecimiento de un mercado interior. Este mercado interior es concretado en el artículo 26 del Tratado de Funcionamiento de la Unión Europea como "un espacio sin fronteras interiores, en el que la libre circulación de mercancías, personas, servicios y capitales estará garantizada". Libertades a las que se dedica el Título IV del TFUE, y que tienen un impacto directo sobre la fiscalidad, ya que limitan y condicionan las cláusulas anti-elusión que, unilateralmente, puedan establecer los Estados. Unas libertades que manifiestan la tensión entre la protección del mercado común y el interés fiscal

\footnotetext{
47 LÓPEZ ESPADAFOR, Carlos María. Recorrido transnacional de la soberanía tributaria. Cuadernos de Derecho Transnacional, p. 306330, mar. 2018. DOI: https://doi.org/10.20318/cdt.2018.4124. p. 315.

48 CONTASTINESCO, Leontin-Jean. La problemática tributaria de la Comunidad Económica Europea. Hacienda Pública Española, n. 57, p. 163-176, 1979. p. 164.
} 
de los Estados, entre globalización e integración y la soberanía y la unilateralidad.

De este modo, surgen limitaciones a los Estados, quienes, por ejemplo para establecer normas antielusión, deben superar el examen del Tribunal de Justicia de la Unión demostrando la existencia de interés general y superando la adecuación y no extralimitación de la medida. Un auténtico checking balance entre el bien protegido, las cuatro libertades comunitarias y el interés general perseguido por la norma antielusión ${ }^{49}$.

La única solución son los esfuerzos por armonización fiscal desde la Unión, que suelen recibir un tratamiento hostil de los Estados. Una Unión Europea en la que algunos ámbitos, como el aduanero o la tributación indirecta a logrado más avances, son mucho más limitados en el ámbito de la imposición directa.

En el plano tributario debemos considerar que las atribuciones referentes a la soberanía fiscal son notablemente parcas, y los intentos de armonización (término en sí mismo interesante al aunar la aspiración de homogeneizar la regulación de materias en un contexto de diversidad política) habitualmente son considerados insuficientes por la doctrina.

Por ejemplo, en el tratado de funcionamiento se regulan varias disposiciones de carácter fiscal, en la que se establecen unos principios básicos de integración, como la prohibición de gravar directa o indirectamente los productos de los demás Estados miembros con ánimo proteccionista, así como la prohibición de beneficiarse de ventajas fiscales a las exportaciones (por distorsionar la libre competencia).

Especialmente significativo resulta en este sentido el art. 115 del TFUE, en el que se establece que

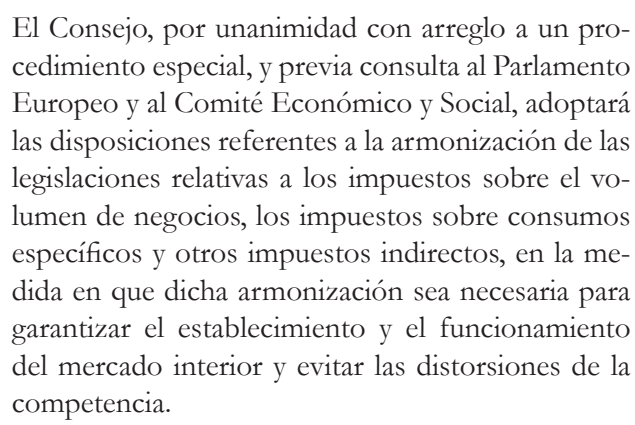

49 SANZ GÓMEZ, Rafael. Las cláusulas anti-abuso específicas tributarias frente a las libertades de circulación de la Unión Europea. Barcelona: Bosch, 2010. p. 167.
Consideremos que la aplicación del procedimiento especial supone de facto una muy notable limitación a las opciones de integración, siendo significativo que se recurra al criterio de la unanimidad, que implica otorgar a cada Estado miembro un derecho de veto en esta materia. Sin embargo, en nuestra opinión, las sucesivas oleadas integradoras de la Unión, desde la construcción del mercado único a la zona euro, parecen conducir a una paradoja irresoluble. La necesidad de atribuir más competencias a la Unión, y particularmente en el ámbito fiscal y la incapacidad para otorgar mayores competencias y avanzar en la integración, choca lógicamente con la voluntad de los Estados miembros de mantener una independencia política. Efectivamente, la atribución de toda la soberanía fiscal a la Unión europea, (al menos en términos equivalentes a los de un Estado Federal) conduciría a limitaciones prácticas en las políticas de los Estados respecto a los que se carece por el momento auténtica voluntad política de crear.

El avance en la integración europea, especialmente en algunos ámbitos, ha llevado a producir asimetrías en algunos ámbitos. Así, mientras la política monetaria y la política de equilibrio presupuestario sí las encontramos en el ámbito de la política europea, los restantes elementos de la política económica quedan en los Estados miembros. Ciertamente se intentan articular mecanismos de coordinación dentro de la Unión, pero la política monetaria constituye sin duda el ámbito más plenamente europeizado del ámbito económico, teniendo por objetivo fundamental el mantenimiento de la estabilidad de los precios.

La política presupuestaria es el otro gran ámbito incorporado a partir del año 2010, a causa de la crisis de deuda soberana. Su fundamento se encuentra fuera del entramado de la Unión, en el que los Estados miembros utilizan instituciones de la Unión para un nuevo fin. Se firma así el Tratado de Estabilidad, Coordinación y Gobernanza de 2012, ajeno a la Unión tanto por contradicciones con él (la prohibición de que el Banco Central Europeo financie a Estados del art. 124) como para evitar el veto británico.

Las restantes medidas políticas corresponden a los Estados, art. 120 TFUE, por el que éstos "llevarán a cabo sus políticas públicas con vistas a contribuir a la realización de los objetivos de la Unión”, con la única limitación de respetar los principios básicos como las libertades comunitarias o la libre competencia. Esta 
atribución exige coordinación en el Consejo, que por Recomendación podrá adoptar orientaciones generales y supervisar la evolución y coherencia de las políticas económicas. Se crea un sistema de supervisión multilateral en el que tienen cabida políticas de carácter fiscal, con capacidad de sanción.

De este modo vemos que las limitaciones para avanzar en la integración fiscal están en los propios Estados miembros, que exigen para la ratificación de los Tratados la regla de la unanimidad (que no obstante ha ido perdiendo notable fuerza en el panorama general europeo). Unos Estados que en ocasiones acusan de la Unión de inacción o falta de resolución sobre materias que no tiene atribuidas, o recibe acusaciones de falta de solidaridad. Incluso en relación con la financiación desde la Unión a los Estados en situaciones de crisis, (tanto durante la crisis de deuda como en la actual crisis del coronavirus), los criterios de unanimidad se mantuvieron y se mantienen. De hecho, los intentos de llegar a acuerdos en el seno de la Unión en algunos temas como la fiscalidad de actividades digitales fracasan. Sólo queda la actuación del Tribunal de Justicia de la Unión Europea en caso de la incompatibilidad ya señalada con los principios de la Unión, si se produjese.

Es por ello que podemos ver en el ejemplo de la Unión Europea el conflicto entre la aspiración integradora, también a nivel fiscal, con la protección de las competencias soberanas de sus Estados. Tan cierto es que la Unión implica fuertes limitaciones a la soberanía fiscal de los Estados miembros, como las herramientas con las que éstos se han dotado para garantizar su soberanía fiscal y la defensa de su interés nacional.

\section{Conclusiones}

Hemos comenzado este trabajo planteando la duda de si estamos realmente en una fase de desglobalización o, como afirman otra parte de autores, una nueva forma de globalización. Era necesario partir de esta diferenciación conceptual, aunque por el momento la cuestión no sea pacífica. Algunos autores consideran que para el mantenimiento la economía mundial neoliberal es necesaria la cooperación política multilateral, al menos entre los actores principales. Quizá estamos en lo que señalaba Appelbaum, como las dos nuevas tendencias de la nueva globalización: unilateralismo y libre mercado. En cualquier caso, parece claro que estamos entrando en una nueva fase con fuertes tendencias a prácticas unilaterales. Unas prácticas que son particularmente intensas en el ámbito fiscal.

La globalización económica resulta inverosímil que pueda lograr una integración política, especialmente en un momento en que parecen renacer los viejos sentimientos nacionales. A nivel de fiscalidad internacional, y en contraste con propuestas de algunos autores ${ }^{50}$, se ha sido incapaz de construir un conjunto de normas de Derecho Internacional General en materia tributaria. Los acuerdos son muy limitados y siempre estableciendo cautelas (por otra parte, lógicas) y cláusulas de salvaguarda que garanticen la retención de las potestades soberanas y muy especialmente la soberanía fiscal.

Hemos puesto dos supuestos concretos, la falta de acuerdo a la hora de coordinarse para someter a gravamen la economía digital y la falta de acuerdo para determinar un concepto uniforme sobre el concepto "Paraíso fiscal". Además, hemos expuesto muy someramente las limitaciones que la integración fiscal padece en la Unión Europea, especialmente en cuanto al ámbito de la imposición directa se refiere. Ejemplos en los que hemos querido poner en valor cómo el ámbito fiscal a nivel internacional es uno en los que el unilateralismo tiene una incidencia especialmente notable. Existen de hecho otros, como por ejemplo el carácter unilateral del Tratado FATCA de Estados Unidos, que implica la aplicación de una Ley interna, sobre cumplimiento tributario de cuentas extranjeras y efectos extraterritoriales ${ }^{51}$.

En materia fiscal hemos podido apreciar algunas de las principales trabas a lo que autores como López Espadafor (p. 330) denomina "globalización fiscal". Unas trabas que manifiestan la permeabilidad que el ámbito tributario tiene a prácticas unilaterales, especialmente reforzada dada su estrecha conexión con la soberanía, y las dificultades aparentemente irresolubles a las que se enfrenta el Derecho internacional tributario para alcanzar acuerdos.

Sin duda nos encontramos en una fase en que algunos Estados, esencialmente Estados desarrollados del

\footnotetext{
50 LÓPEZ ESPADAFOR, Carlos María. Recorrido transnacional de la soberanía tributaria. Cuadernos de Derecho Transnacional, p. 306330, mar. 2018. DOI: https://doi.org/10.20318/cdt.2018.4124. p. 308.

51 En este sentido, como medida unilateral y lesiva de la soberanía de otros Estadso: MORRIS, Robert. FATCA and the new birth of American Empire. New York: More Freedom Foundation, 2013.
} 
bloque occidental, son favorables a una homogeneización fiscal a nivel global. La habitualidad de las prácticas de carácter unilateral nos hace ser pesimistas. Resulta más plausible una aceptación dentro de ese grupo de Estados de un aparente acuerdo que en la práctica derive en la aplicación de criterios diversos y al incremento de la inseguridad jurídica. Al menos, mientras el soft law siga sin ser de obligado cumplimiento.

Por ello, las prácticas unilaterales las consideramos especialmente intensas en el ámbito tributario. La tendencia actual hacia el unilateralismo encuentra especial eco en esta rama del Derecho y las propuestas de armonización fiscal internacional deben entenderse como la pugna entre Estados por lograr imponer, con mejor o peor fortuna, sus intereses económicos al resto, cuestión clave en la nueva bipolaridad global.

\section{Bibliografía}

APPELBAUM, Richard P.; ROBINSON, William I. (ed.). Critical globalization studies. New York: Routledge, 2005.

BELLO, Walden. Deglobalization: ideas for new world economy (global issues). London: Zed Books, 2001.

BÜHLER, Ottmar. La doble imposición: problemas jurídico-internacionales. Barcelona: Universidad de Barcelona, 1971.

CHAN, Clayton W. Taxation of global e-commerce on the internet: the underlying issues and proposed plans. Minnesota Journal of Global Trade, v. 9, n. 1, p. 233-268, 2000. Disponible en: https://core.ac.uk/download/ pdf/217210515.pdf.

CHRISTIANS, Allison. Sovereignty, taxation, and social contract. Legal Studies Research Paper Series, paper n. 1063, University of Wisconsin Law School, aug. 2008. p. 1-50. Disponible en: https://papers.ssrn.com/sol3/ papers.cfm?abstract_id $=1259975$.

CONTASTINESCO, Leontin-Jean. La problemática tributaria de la Comunidad Económica Europea. Hacienda Pública Española, n. 57, p. 163-176, 1979.

DAVID, Thomaz Delgado; SILVA, Maria Beatriz Oliveira da; BARCELLOS, Rosane Beatris da Rocha. A dimensâo jurídica do imperalismo na (des)orden global capitalista: uma análise com base na crítica marxista ao direito internacional e ás relaçôes político-económicas de dominaçâo e dependência. Revista de Direito Internacional, Brasilia, v. 15, n. 3, p. 379-440, 2018. Disponible en: https://www.publicacoesacademicas.uniceub.br/rdi/ article/view/5882/pdf.

GIDDENS, Anthony. The consequences of modernity. Cambridge: Polity Press, 1991.

GILPIN, Robert. The challenge of global capitalism in the $21^{\text {st }}$ century. Princeton: Princeton University Press, 2002.

HAASS, Richard N. Globalization's consequences and challeges for governance, en globalization, governance and civil society. Japan Center for International Exchange, 1998. Disponible en: https://www.jcie.org/analysis/booksreports/globalization/.

HELD, David; MCGREW, Anthony G. (ed.). The global transformations reader: an introduction to the globalization debate. Blackwell Publishers, 2000.

JAMES, Harold. Deglobalization as a global change. Centre for international Governance Innovation papers, n. 135, june 2017. Disponible en: https://www.cigionline.org/sites/default/files/documents / Paper $\% 20$ no.135WEB_1.pdf.

JAMES, Harold. Deglobalization: the rise of disembedded unilateralism. Annual Review of Financial Economics, v. 10, p. 219-237, 2018. DOI: https://doi-org.ezproxy. uned.es/10.1146/annurev-financial-110217-022625.

JÜRGEN, Stehn. Leviathan in cyberspace: hot to tax e-commerce. Kieler Diskussionsbeiträge, n. 384, The Open Access Publication Server of the ZBW, Leibniz Information Centre for Economics, 2002. Disponible en: https://www.researchgate.net/publication/45122976_ Leviathan_in_cyberspace_how_to_tax_e-commerce.

KAUR, Karamjeet. Globalization \& deglobalization. Chandigarh: Sapatrishi Publications Chandigarh, 2020.

KELLEY, Christopher S. Rhetoric and Reality? Unilateralism and the Obama Administration. Social, Economic, and Political Transition in America: Retrospective on the "Era of Obama", v. 93, n. 5, special issue, p. 1146-1160, dec. 2012. Disponible en: https://www.jstor.org/stable/42864120.

LECHNER, Frank J.; BOLI, John. The globalization reader. Hoboken: Wiley, 2012.

LÓPEZ ESPADAFOR, Carlos María. Recorrido transnacional de la soberanía tributaria. Cuadernos de Derecho 
Transnacional, p. 306-330, mar. 2018. DOI: https://doi. org/10.20318/cdt.2018.4124.

MARICHAL, Maria Eugenia. La OMC y el proceso de globalización de la regulación alimentaria. Revista de Direito Internacional, Brasilia, v. 12, n. 2, p. 306-321, 2014. Disponible en: https://www.publicacoesacademicas. uniceub.br/rdi/article/view/3146/pdf.

MARTIN, Mervyn. Keeping it real: debunking the deglobalization Myth, Brexit and Trump: "Lessons" on integration. Journal of International Trade Law and Policy, v. 17, n. $1 / 2$, p. 62-68, 2019. Disponible en: http://www. emeraldinsight.com/1477-0024.htm.

MORAWASKA, Eva. Transnationalism. In: WATERS, Mary C.; UEDA, Reed (ed.). The new americans: a guide to immigration since 1965. Cambridge: Harvard University Press, 2007.

MORRIS, Robert. FATCA and the new birth of American Empire. New York: More Freedom Foundation, 2013.

MUÑIZ PÉREZ, Julio César. Brexit y la fractura del statu quo. Revista de Pensamiento Estratégico y Seguridad CISDE, v. 5, n. 2, p. 63-79, 2020. Disponible en: http:// uajournals.com/ojs/index.php/cisdejournal/article/ view/636.

MUÑIZ PÉREZ, Julio César. En busca del paraíso perdido: los paraísos fiscales hoy. Cizur Menor: Aranzadi, 2021.

SANZ GÓMEZ, Rafael. Las cláusulas anti-abuso especificas tributarias frente a las libertades de circulación de la Unión Europea. Barcelona: Bosch, 2010.

SCHUMAN, Robert. Declaración del 9 de mayo de 1950 pronunciada por Robert Schuman. Cuestiones sobre Europa, Fondation Robert Schuman n. 204, p. 1-3, 2011. Disponible en: https://www.robert-schuman.eu/ es/doc/questions-d-europe/qe-204-es.pdf.

SOETE, Luc; KAMP, Karin. The bit tax. The case for further research. Science and Public Policy, v. 23, issue 6, p. 353-360. Disponible en: https://doi.org/10.1093/ spp/23.6.353.

SOUZA, Lucas Silva de; SALDANHA, Jânia Maria Lopes. O direito internacional do desenvolvimento e suas raíces imperialistas no contexto do pluralismo normativo: por un paradigma libertario e nâo (neo)liberal. Revista de Direito Internacional, Brasilia, v. 16, n. 1, p. 200-222. Disponible en: https://www.publicacoesacademicas. uniceub.br/rdi/article/view/5928/pdf.
TAGO, Atsushi. Multilateralism, Bilateralism, and Unilateralism in Foreign Policy. Oxford Research Encyclopedias, 2017. Disponible en: https://doi.org/10.1093/acrefore/9780190228637.013.449.

VAN BERGEIJK, Peter A. G. Deglobalization 2.0: trade and openness during the great depression and the global recession. Cheltenham: Edward Elgar Publishing, 2019.

VAN BERGEIJK, Peter A. G. On the brink of deglobalization again. Cambridge Journal of Regions, Economy and Society, v. 11, p. 59-72, 2018.

WARD, Don. How to protect your assets legally with an offshore Trust or International Business Corporation. London: Financial Bureau, 2013.

WILLIAM, Jeffrey. Winners and losers over two centuries of globalization. MA: National Burean of Economic Research Working, paper 9161, 2002. Disponible en: https://www.researchgate.net/publication/5197133_ Winners_and_Losers_Over_Two_Centuries_of_Globalization.

WILLIAMSON, Jeffrey G. Globalization, labor markets and policy backlash in the past. Journal of economic perspectives, v. 12 , n. 4, p. 51-72, 1998. Disponible en: https:/ / www.aeaweb.org/articles?id=10.1257/jep.12.4.51. 
Para publicar na Revista de Direito Internacional, acesse o endereço eletrônico www.rdi.uniceub.br ou www.brazilianjournal.org.

Observe as normas de publicação, para facilitar e agilizar o trabalho de edição. 